\title{
Endoscopic biliary stenting for unresectable malignant hilar obstruction
}

\author{
Mitsuharu Fukasawa $^{1} \cdot$ Shinichi Takano $^{1} \cdot$ Hiroko Shindo $^{1} \cdot$ Ei Takahashi $^{1} \cdot$ \\ Tadashi Sato $^{1} \cdot$ Nobuyuki Enomoto ${ }^{1}$
}

Received: 15 August 2017 / Accepted: 15 September 2017 / Published online: 19 October 2017

(C) Japanese Society of Gastroenterology 2017

\begin{abstract}
Palliative drainage is the primary treatment option for unresectable malignant hilar biliary obstruction (UMHBO) to improve the prognosis and quality of life. Currently, endoscopic biliary drainage is considered as a first-line treatment for UMHBO as well as for distal biliary obstruction. Self-expanding metal stents (SEMSs) are preferred over plastic stents (PSs) in patients with life expectancy of $>3$ months. However, endoscopic treatment of UMHBO is often more challenging and complex than that of distal biliary obstruction. Although no consensus exists on the optimal method for biliary drainage because of the lack of well-designed, large-scale randomized control trials, several essential aspects of various optimal methods have been studied. Presently, technological developments in this field are under way and newly designed or modified stenting devices for UMHBO are being developed. In this review, we assess the optimal stenting strategy for UMHBO based on the previous literature, focusing on the stent type (PS vs SEMS), the liver volume to be drained, unilateral (single) vs bilateral (multiple) stent deployment, and bilateral stenting method (stent-in-stent vs side-by-side).
\end{abstract}

Keywords Biliary drainage $\cdot$ Hilar biliary obstruction . Unilateral stenting $\cdot$ Bilateral stenting $\cdot$ Drainage liver volume

Mitsuharu Fukasawa

fmitsu@yamanashi.ac.jp

1 First Department of Internal Medicine, Faculty of Medicine, University of Yamanashi, 1110, Shimokato, Chuo,

Yamanashi 409-3898, Japan

\author{
Abbreviations \\ UMHBO Unresectable malignant hilar biliary \\ obstruction \\ DBO Distal biliary obstruction \\ SEMS Self-expandable metal stent \\ PS Plastic stent \\ SIS Stent-in-stent \\ SBS Side-by-side \\ RCT Randomized controlled trial \\ RBO Recurrent biliary obstruction
}

\section{Introduction}

The management of obstructive jaundice and cholangitis is crucial for enhancing the prognosis and quality of life of patients with unresectable malignant hilar biliary obstruction (UMHBO). The three established methods for palliation of UMHBO are endoscopic drainage, percutaneous transhepatic drainage, and surgical bypass. Currently, endoscopic drainage is preferred because of minimal invasiveness, less mortality, shorter hospitalization period, and recent progress in endoscopic devices. However, endoscopic stenting for the treatment of UMHBO is still challenging with no definite consensus on the optimal approach. Controversy still exists over the optimal type of stent, drainage area (unilateral or bilateral drainage), required drained liver volume, and bilateral stenting method [stent-in-stent (SIS) or side-by-side (SBS)]. With ongoing technological developments, newly designed or modified self-expanding metal stents (SEMSs) are under way to overcome current limitations. Here, we review the literature concerning the current strategies and technical issues of endoscopic biliary drainage for patients with UMHBO. 


\section{Plastic versus self-expandable metallic stents}

The types of stents used for drainage in UMHBO include plastic stents (PSs) and SEMSs. Table 1 presents data of three randomized control trials (RCTs) [1-3] and one prospective observational study [4] comparing results of PSs and SEMSs. Although the technical success rate was similar in both, the SEMS had a longer time to recurrent biliary obstruction (RBO) and fewer requirements for reintervention. Despite being more expensive than PSs, SEMSs have superior cost-effectiveness because of fewer occlusions, fewer reinterventions, shorter hospital stay, and lower antibiotic use than PSs, when a patient's expected survival is $>4-6$ months. In an RCT comparing PSs and SEMSs, Mukai et al. [3] reported the 6-month patency rate was significantly higher in the SEMS group than in the PS group (81 vs $20 \%, p=0.0012$ ). Kaplan-Meier analysis demonstrated a significantly longer patency in the SEMS group than in the PS group ( $p=0.0002)$; the $50 \%$ patency period was 359 and 112 days in the SEMS group and PS group, respectively. The mean number of reinterventions for stent failures was significantly lower in the SEMS group (0.63 times/patient) than in the PS group (1.80 times/patient; $p=0.0008$ ). The overall cost for treatment was significantly lower in the SEMS group than in the PS group $(p=0.0222)$. Furthermore, the Asia-Pacific Consensus [5] recommends biliary palliation with an SEMS for patients with predicted survival of $>3$ months and Bismuth type II-IV hilar cholangiocarcinoma. PSs are recommended as temporary drainage for patients with cholangitis and undetermined treatment plan.

\section{Unilateral (single) versus bilateral (multiple) stenting}

Restoration of the bile flow is one of the core objectives of palliative treatment for UMHBO. Although unilateral or single stenting is technically easier and less expensive than bilateral stenting, bilateral or multiple stenting is more physiological and has superiority in drainage liver volume compared to unilateral stenting. Currently, there exists no definite consensus on the best endoscopic drainage method for performing unilateral or bilateral stenting in patients with UMHBO. To date, three RCTs [3, 6, 7] have compared outcomes of unilateral and bilateral stenting (Table 2). In an RCT conducted by De Palma et al. [6] that compared the results of unilateral and bilateral PS deployment, unilateral stenting demonstrated a significantly higher rate of technical success ( 89 vs $77 \% ; p=0.041$ ), clinical success ( 81 vs $73 \% ; p=0.048)$, and a significantly lower rate of early complication (19 vs $27 \%$; $p=0.026)$ than bilateral stenting. Therefore, the authors concluded that the insertion of multiple stents as a routine procedure in patients with UMHBO would not be justifiable. Mukai et al. [3] reported an RCT of PSs and SEMSs for UMHBS, and by analyzing comparative data for unilateral and bilateral stenting, they revealed that no significant difference exists in the stent patency between unilateral and bilateral stenting. The success rate of endoscopic reintervention was significantly higher in unilateral stenting than in bilateral stenting (100 vs $68 \% ; p=0.027$ ). Although unilateral stenting was more advantageous in terms of reintervention, approximately $50 \%$ of patients with primary unilateral drainage to treat jaundice or cholangitis required further bilateral drainage. Endoscopic bilateral metal stenting is considered to be technically more challenging than unilateral stenting. However, with the recent advancements in SEMS devices and technical improvement, the technical success rate of bilateral SEMS placement has improved remarkably. Recent studies have revealed higher technical success rates (90-100\%) in bilateral SEMS deployment [8-10]. Most recently, Lee et al. [7] reported an RCT comparing outcomes of unilateral and bilateral stenting for high-grade UMHBO (Bismuth type II-IV). Although technical success rate was equivalent (unilateral $100 \%$ vs

Table 1 Comparative prospective studies between plastic stents and self-expandable metallic stents for malignant hilar biliary obstruction

\begin{tabular}{|c|c|c|c|c|c|c|c|}
\hline Author & Year & Study design & Stent & $\begin{array}{l}\text { No. of } \\
\text { subjects }\end{array}$ & $\begin{array}{l}\text { Technical suc- } \\
\text { cess }(\%)\end{array}$ & $\begin{array}{l}\text { Time to recurrent biliary } \\
\text { obstruction (months) }\end{array}$ & $\begin{array}{l}\text { No. of } \\
\text { re-inter- } \\
\text { ventions }\end{array}$ \\
\hline \multirow[t]{2}{*}{ Wagner et al. [1] } & \multirow[t]{2}{*}{1993} & \multirow[t]{2}{*}{ RCT } & PS & 9 & 89 & \multirow[t]{2}{*}{ NA } & 2.4 \\
\hline & & & MS & 11 & 100 & & 0.4 \\
\hline \multirow[t]{2}{*}{ Perdue et al. [4] } & \multirow[t]{2}{*}{2008} & \multirow[t]{2}{*}{ Prospective cohort } & PS & 28 & 85 & \multirow[t]{2}{*}{ NA } & \multirow[t]{2}{*}{ NA } \\
\hline & & & USEMS & 34 & 97 & & \\
\hline \multirow[t]{2}{*}{ Sangchan et al. [2] } & \multirow[t]{2}{*}{2012} & \multirow[t]{2}{*}{ RCT } & PS & 54 & 85 & 3.4 & \multirow[t]{2}{*}{ NA } \\
\hline & & & USEMS & 54 & 83 & 1.2 & \\
\hline \multirow[t]{2}{*}{ Mukai et al. [3] } & \multirow[t]{2}{*}{2013} & \multirow[t]{2}{*}{$\mathrm{RCT}$} & PS & 30 & 100 & 12 & 1.8 \\
\hline & & & CSEMS & 30 & 100 & 3.7 & 0.6 \\
\hline
\end{tabular}

$R C T$ randomized controlled trial, PS plastic stent, USEMS uncovered self-expandable metallic stent, CSEMS covered self-expandable metallic stent 


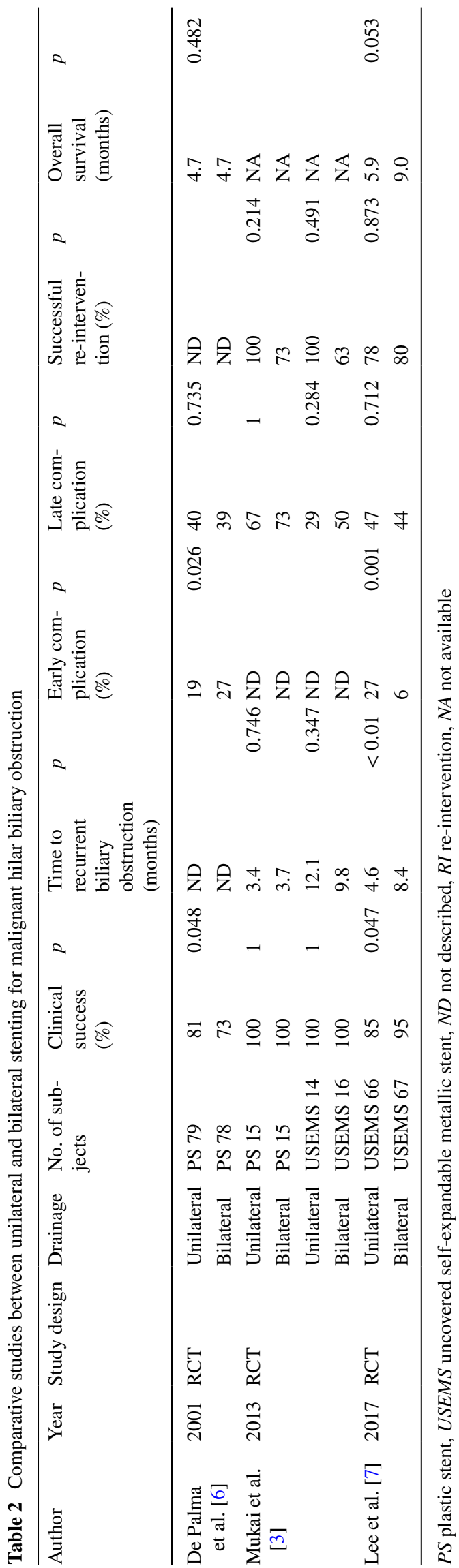

bilateral 95.5\%; $p=0.244)$, bilateral stenting resulted in a higher clinical success rate ( 84.9 vs $95.3 \% ; p=0.047$ ) and lower reintervention rate (60.3 vs $42.6 \% ; p=0.049$ ). Furthermore, RBO posed a significantly higher risk in the unilateral stenting group $(p<0.01)$. The survival probability and late adverse events were not different between both groups. To elucidate whether unilateral or bilateral stenting is better in the treatment of UMHBO, further well-designed, large-scale trials are warranted.

\section{Drainage liver volume}

The right, left, and caudate lobes of the liver occupy approximately 55-60, 30, and $10 \%$ of the liver volume, respectively [11]. The liver volume, which is drained by stent deployment, depends on the liver volume distribution and extent of a malignant biliary stricture. While both lobes can be drained using a single stent alone in patients with Bismuth type I stricture, multiple stents are required for draining both lobes in patients with Bismuth type II-IV. Although unilateral stenting is a simpler and safer method than bilateral stenting, there is a limitation on drained liver volume for an advanced stricture. A previous report showed that only $25 \%$ of the liver volume was sufficient for palliation of jaundice [12]. However, Vienne et al. [13] reported that $\geq 50 \%$ drainage of the liver volume is associated with effective drainage and prolonged survival. They suggested that draining $\geq 50 \%$ of the liver volume, which frequently required bilateral stenting, was a significant predictor of drainage effectiveness in MHBO and a pre-endoscopic retrograde cholangio-pancreatography (ERCP) assessment of hepatic volume distribution of a computed tomography imaging optimized endoscopic procedure. Recently, Takahashi et al. [14] examined the liver volume and preserved liver function for effective biliary drainage in UMHBO. They revealed that drainage volume required for effective drainage in UMHBO was $\geq 33 \%$ in patients with normal liver function and $\geq 50 \%$ in patients with impaired liver function (decompensated liver cirrhosis). On the other hand, multiple stenting to the atrophic area increased the risk of cholangitis as an early adverse event. Therefore, the authors concluded that the use of unilateral or bilateral stenting should be determined on the basis of the drainage volume and function of the liver, and excessive multi-stenting, particularly to the atrophic area, should be avoided to reduce the risk of cholangitis. Lee et al. [15] examined changes in the liver volume after endoscopic stenting in patients with cholangiocarcinoma and revealed that SEMS placement significantly increased the liver volume, particularly within 4-8 weeks. Stenting for hilar strictures demonstrated a greater increase in the liver volume than distal biliary stenting, although the difference was not significant (22.5 vs $11.5 \% ; p=0.091)$. An increase in the liver volume by bilateral stenting was similar to that by unilateral 
stenting. Considering that the liver volume in the stent placement area increases, it might not be necessary to drain all the bile ducts to advanced stricture, especially in Bismuth type IV. The assessment of drainage liver volume before ERCP is imperative for determining the bile duct for drainage and the number of stents for the treatment of UMHBO.

\section{Multiple stenting methods (stent-in-stent or side-by-side)}

Endoscopic bilateral SEMS placement for UMHBO has been considered to be technically challenging. Bilateral SEMS stenting can be performed using the SIS or SBS technique. In the SIS technique, the second SEMS is inserted to the contralateral hepatic duct through the mesh of the first SEMS [16-22]. Conversely, in the SBS technique, two SEMSs are inserted parallel to each other into the right and left hepatic duct [23-26] (Fig. 1). The insertion of the SEMS in the bilateral SBS technique is easier when guidewires are inserted into the right and left hepatic ducts. The primary concern in the SBS technique is overexpansion of the stricture and distal bile duct by two SEMSs. The excessive expansion force of two SEMSs can cause severe pain, acute cholecystitis, and occlusion of the portal vein. Because SIS deployment is more physiological than SBS deployment, two SEMSs can be expanded within the caliber of a single stent. The SIS technique has the advantage of avoiding excessive expansion of the bile duct, particularly for nondilated bile ducts (Table 3). To date, no consensus has been reached on the optimal method when performing bilateral SEMS deployment in patients with UMHBO. Three retrospective studies have been conducted to compare the SIS and SBS techniques. Naitoh et al. [27] compared SIS and SBS deployment in patients with UMHBO who underwent bilateral endoscopic drainage using SEMSs. No significant differences were observed in the technical success (SIS 100\% vs SBS 89\%) and functional success (100 vs 96\%) between the two groups. Cumulative stent patency was significantly longer in the SBS group than in the SIS group (median 469 vs 181 days; $p=0.047$ ); however, the incidence of complications was significantly higher in the SBS group (44 vs $13 \% ; p=0.016)$. Kim et al. [28] retrospectively reviewed the results of patients undergoing bilateral drainage for UMHBO. No significant differences were reported in the successful drainage (SIS $82 \%$ vs SBS $89 \%$ ), early complication (23 vs 32\%), and late complication (50 vs 37\%) between SIS and SBS deployment in UMHBO. On comparing stent patency and survival curves according to bilateral stenting type, patients with SIS and SBS placement did not differ significantly ( $p=0.771$ and 0.769 ). Law et al. [29] retrospectively compared SIS and SBS stenting using the Zilver biliary SEMS with a 6-Fr delivery system. A comparison of the SBS and SIS groups revealed no statistical difference
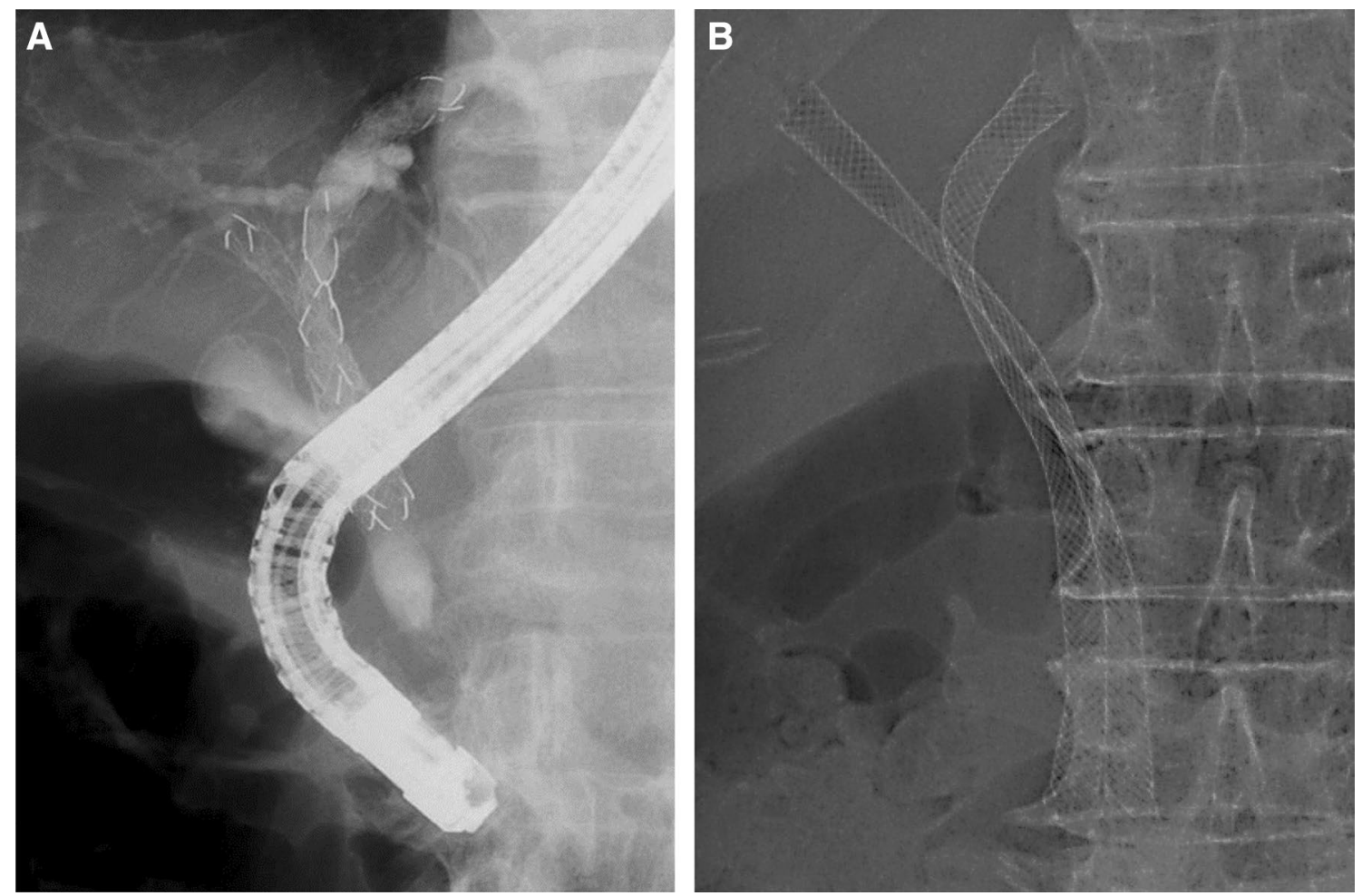

Fig. 1 a Bilateral SEMS deployment by the stent-in-stent technique. b Bilateral SEMS deployment by the side-by-side technique 
Table 3 Advantages and disadvantages of stent-in-stent and side-by-side techniques

\begin{tabular}{lll}
\hline & Stent-in-stent & Side-by-side \\
\hline Advantages & Physiological biliary drainage & Technically simple \\
& Expand within the caliber of a single stent \\
& More than two stentings are available & \\
Technical difficulty & Overexpansion of stricture and distal bile duct \\
Disadvantages & First stent: large open-celled or cross-wired SEMS (hilar & Excess compress of the portal vein and cystic duct \\
Suitable SEMS & Secontl-diameter delivery system
\end{tabular}

with respect to the need for reintervention ( $p=0.31)$, successful reintervention ( $p=0.60)$, or procedural length $(p=0.89)$. These reports have limitations of a retrospective design and small sample size, and no definite consensus has been reached. The development of SEMS devices dedicated to the SIS or SBS technique, and well-designed large-scale RCTs comparing these techniques are warranted.

\section{Progress of SEMS for bilateral stenting}

Newly designed SEMSs are being developed for safe and successful bilateral stenting. The most challenging part of the SIS technique is the insertion of the second SEMS to the contralateral hepatic duct through the mesh of the first SEMS. To overcome this hurdle, a large open-cell wire mesh SEMS (Niti-S large cell D-type; Taewoong Corp., Seoul, Korea) was developed. Kogure et al. [20] demonstrated high technical success rates with large-cell SEMSs in the bilateral SIS technique. A newly designed, closed-cell and cross-wire stent is another SEMS (Bonastent M-Hilar; Standard Sci Tech Inc., Seoul, Korea) dedicated to SIS stenting, which comprises a hook and cross-wired structure on the proximal and distal portions, and only the cross-wired structure on the central portion facilitates the SIS technique [17]. The difficulty of the SBS technique is related to the insertion of the second SEMS along the first SEMS. After deployment of the first SEMS, the subsequent insertion of the second SEMS is often hindered by the first expanded SEMS. Recently, an SEMS with a small-diameter (6-Fr) delivery system (Zilver635; Cook Japan, Tokyo, Japan) was developed to overcome this difficulty. This thin delivery system can facilitate a single-step simultaneous SBS placement through the accessory channel of the duodenoscopy, which allows a high technical success rate for bilateral SBS stenting [29, 30]. The position of the distal ends of the SEMS is under debate. The distal ends of both SEMSs should be placed at the same level in the common bile duct or in the duodenum for future access to reintervention. Furthermore, SEMS with a small-diameter delivery system have an advantage in the
SIS method. This thin delivery can effortlessly pass through the mesh of the first SEMS or stricture, which may facilitate the bilateral stent deployment not only in the SBS technique but also in the SIS technique.

\section{Conclusion}

We reviewed the current status of endoscopic biliary drainage for UMHBO. Although endoscopic stent placement is currently the most ideal palliation method for UMHBO, many issues still remain unresolved. SEMSs are recommended in patients with life expectancy of $>3$ months. However, the optimal drainage approach, such as the drainage area and stenting method, is still under debate. Advancements in devices and techniques for biliary drainage and further well-designed, large-scale studies are warranted for resolving these issues.

\section{Compliance with ethical standards}

Conflict of interest Mitsuharu Fukasawa, Shinichi Takano, Hiroko Shindo, Ei Takahashi, Tadashi Sato and Nobuyuki Enomoto declare that they no conflict of interest.

Human Rights All Procedures followed have been performed in accordance with the ethical standards laid down in the 1964 Declaration of Helsinki and its later amendments.

Informed consent The study does not involve human subjects and does not apply to giving informen consent.

\section{References}

1. Wagner HJ, Knyrim K, Vakil N, et al. Plastic endoprostheses versus metal stents in the palliative treatment of malignant hilar biliary obstruction. A prospective and randomized trial. Endoscopy. 1993;25(3):213-8 (PubMed PMID: 7686100. Epub 1993/03/01. eng).

2. Sangchan A, Kongkasame W, Pugkhem A, et al. Efficacy of metal and plastic stents in unresectable complex hilar cholangiocarcinoma: 
a randomized controlled trial. Gastrointest Endosc. 2012;76(1):93-9 (PubMed PMID: 22595446. Epub 2012/05/19. eng).

3. Mukai T, Yasuda I, Nakashima M, et al. Metallic stents are more efficacious than plastic stents in unresectable malignant hilar biliary strictures: a randomized controlled trial. J Hepatobiliary Pancreat Sci. 2013;20(2):214-22 (PubMed PMID: 22415652. Epub 2012/03/15. eng).

4. Perdue DG, Freeman ML, DiSario JA, et al. Plastic versus selfexpanding metallic stents for malignant hilar biliary obstruction: a prospective multicenter observational cohort study. J Clin Gastroenterol. 2008;42(9):1040-6 (PubMed PMID: 18719507. Epub 2008/08/23. eng).

5. Rerknimitr R, Angsuwatcharakon $\mathrm{P}$, Ratanachu-ek T, et al. AsiaPacific consensus recommendations for endoscopic and interventional management of hilar cholangiocarcinoma. J Gastroenterol Hepatol. 2013;28(4):593-607 (PubMed PMID: 23350673).

6. De Palma GD, Galloro G, Siciliano S, et al. Unilateral versus bilateral endoscopic hepatic duct drainage in patients with malignant hilar biliary obstruction: results of a prospective, randomized, and controlled study. Gastrointest Endosc. 2001;53(6):547-53 (PubMed PMID: 11323577. Epub 2001/04/27. eng).

7. Lee TH, Kim TH, Moon JH, et al. Bilateral versus unilateral placement of metal stents for inoperable high-grade malignant hilar biliary strictures: a multicenter, prospective, randomized study (with video). Gastrointest Endosc. 2017. doi:10.1016/j.gie.2017.04.037 (PubMed PMID: 28479493)

8. Liberato MJ, Canena JM. Endoscopic stenting for hilar cholangiocarcinoma: efficacy of unilateral and bilateral placement of plastic and metal stents in a retrospective review of 480 patients. BMC Gastroenterol. 2012;09(12):103 (PubMed PMID: 22873816. Pubmed Central PMCID: PMC3476445. Epub 2012/08/10. eng).

9. Naitoh I, Ohara H, Nakazawa T, et al. Unilateral versus bilateral endoscopic metal stenting for malignant hilar biliary obstruction. J Gastroenterol Hepatol. 2009;24(4):552-7 (PubMed PMID: 19220678. Epub 2009/02/18. eng).

10. Iwano $\mathrm{H}$, Ryozawa $\mathrm{S}$, Ishigaki $\mathrm{N}$, et al. Unilateral versus bilateral drainage using self-expandable metallic stent for unresectable hilar biliary obstruction. Dig Endosc Off J Jpn Gastroenterol Endosc Soc. 2011;23(1):43-8 (PubMed PMID: 21198916. Epub 2011/01/05. eng).

11. Bismuth $\mathrm{H}$. Surgical anatomy and anatomical surgery of the liver. World J Surg. 1982;6(1):3-9 (PubMed PMID: 7090393. Epub 1982/01/01. eng).

12. Dowsett JF, Vaira D, Hatfield AR, et al. Endoscopic biliary therapy using the combined percutaneous and endoscopic technique. Gastroenterology. 1989;96(4):1180-6 (PubMed PMID: 2925062. Epub 1989/04/01. eng).

13. Vienne A, Hobeika E, Gouya H, et al. Prediction of drainage effectiveness during endoscopic stenting of malignant hilar strictures: the role of liver volume assessment. Gastrointest Endosc. 2010;72(4):728-35 (PubMed PMID: 20883850. Epub 2010/10/05. eng).

14. Takahashi E, Fukasawa M, Sato T, et al. Biliary drainage strategy of unresectable malignant hilar strictures by computed tomography volumetry. World J Gastroenterol. 2015;21(16):4946-53 (PubMed PMID: 25945008. Pubmed Central PMCID: PMC4408467. Epub 2015/05/07. eng).

15. Lee $\mathrm{CH}$, Kim $\mathrm{SH}$, Kim IH, et al. Endoscopic stenting in bile duct cancer increases liver volume. Gastrointest Endosc. 2014;80(3):44755 (PubMed PMID: 24679659. Epub 2014/04/01. eng).

16. Kawamoto H, Tsutsumi K, Fujii M, et al. Multiple stenting in a patient with a high-grade malignant hilar biliary stricture: endoscopic four-branched partial stent-in-stent deployment of metallic stents. Endoscopy. 2007;39(Suppl 1):E167-8 (PubMed PMID: 17614071. Epub 2007/07/07. eng).

17. Park DH, Lee SS, Moon JH, et al. Newly designed stent for endoscopic bilateral stent-in-stent placement of metallic stents in patients with malignant hilar biliary strictures: multicenter prospective feasibility study (with videos). Gastrointest Endosc. 2009;69(7):1357-60 (PubMed PMID: 19481654. Epub 2009/06/02. eng).

18. Kim JY, Kang DH, Kim HW, et al. Usefulness of slimmer and opencell-design stents for endoscopic bilateral stenting and endoscopic revision in patients with hilar cholangiocarcinoma (with video). Gastrointest Endosc. 2009;70(6):1109-15 (PubMed PMID: 19647244. Epub 2009/08/04. eng).

19. Chahal P, Baron TH. Expandable metal stents for endoscopic bilateral stent-within-stent placement for malignant hilar biliary obstruction. Gastrointest Endosc. 2010;71(1):195-9 (PubMed PMID: 19945101. Epub 2009/12/01. eng).

20. Kogure H, Isayama H, Nakai Y, et al. Newly designed large cell Niti-S stent for malignant hilar biliary obstruction: a pilot study. Surg Endosc. 2011;25(2):463-7 (PubMed PMID: 20602139. Epub 2010/07/06. eng).

21. Hwang JC, Kim JH, Lim SG, et al. Y-shaped endoscopic bilateral metal stent placement for malignant hilar biliary obstruction: prospective long-term study. Scand J Gastroenterol. 2011;46(3):326-32 (PubMed PMID: 21082874. Epub 2010/11/19. eng).

22. Lee TH, Moon JH, Kim JH, et al. Primary and revision efficacy of cross-wired metallic stents for endoscopic bilateral stent-instent placement in malignant hilar biliary strictures. Endoscopy. 2013;45(2):106-13 (PubMed PMID: 23212727. Epub 2012/12/06. eng).

23. Dumas R, Demuth N, Buckley M, et al. Endoscopic bilateral metal stent placement for malignant hilar stenoses: identification of optimal technique. Gastrointest Endosc. 2000;51(3):334-8 (PubMed PMID: 10699784. Epub 2000/03/04. eng).

24. Cheng JL, Bruno MJ, Bergman JJ, et al. Endoscopic palliation of patients with biliary obstruction caused by nonresectable hilar cholangiocarcinoma: efficacy of self-expandable metallic Wallstents. Gastrointest Endosc. 2002;56(1):33-9 (PubMed PMID: 12085032. Epub 2002/06/27. eng).

25. Chennat J, Waxman I. Initial performance profile of a new $6 \mathrm{~F}$ self-expanding metal stent for palliation of malignant hilar biliary obstruction. Gastrointest Endosc. 2010;72(3):632-6 (PubMed PMID: 20579991. Epub 2010/06/29. eng).

26. Lee TH, Park DH, Lee SS, et al. Technical feasibility and revision efficacy of the sequential deployment of endoscopic bilateral sideby-side metal stents for malignant hilar biliary strictures: a multicenter prospective study. Dig Dis Sci. 2013;58(2):547-55 (PubMed PMID: 22886596. Epub 2012/08/14. eng).

27. Naitoh I, Hayashi K, Nakazawa T, et al. Side-by-side versus stentin-stent deployment in bilateral endoscopic metal stenting for malignant hilar biliary obstruction. Dig Dis Sci. 2012;57(12):3279-85 (PubMed PMID: 22732832. Epub 2012/06/27. eng).

28. Kim KM, Lee KH, Chung YH, et al. A comparison of bilateral stenting methods for malignant hilar biliary obstruction. Hepatogastroenterology. 2012;59(114):341-6 (PubMed PMID: 22353496. Epub 2012/02/23. eng)

29. Law R, Baron TH. Bilateral metal stents for hilar biliary obstruction using a 6Fr delivery system: outcomes following bilateral and side-by-side stent deployment. Dig Dis Sci. 2013;58(9):2667-72 (PubMed PMID: 23625287).

30. Kawakubo K, Kawakami H, Kuwatani M, et al. Single-step simultaneous side-by-side placement of a self-expandable metallic stent with a 6-Fr delivery system for unresectable malignant hilar biliary obstruction: a feasibility study. J Hepatobiliary Pancreat Sci. 2015;22(2):151-5 (PubMed PMID: 25345586. Epub 2014/10/28. eng). 